\title{
L'arqueologia com a element constructor de la identitat nacional
}

Carlota Vidal Sànchez

carlotasanchezvidal@ub.edu

Universitat de Barcelona

Facultat d'Història

Departament d'Història i Arqueologia

Carrer de Montalegre, 6

08001 Barcelona

Francisco Gracia Alonso, La construcción de una identidad nacional arqueología, patrimonio y nacionalismo en Cataluña (I850-1939), Barcelona, Edicions de la Universitat de Barcelona, 2018.

Ja fa dècades que el control del discurs historiogràfic va esdevenir una fita política en lloc de científica. No es tracta de la disputa entre dos models interpretatius del passat, sinó de la necessitat de control d'un relat sobre la identitat nacional, la pàtria comuna i els orígens de la seva unitat. La història i la intencionalitat de la seva revisió, que no passa per la seva anàlisi acadèmica, formen part indissoluble dels discursos polítics que actualment circulen pels grans mitjans de comunicació i que són assumits per extenses capes de població com a realitats inqüestionables. L'arqueologia, així com succeeix amb la història, no està pas lliure d'aquesta utilització partidista, fet que resulta contraproduent per a la ciència. Aquesta circumstància, lluny de trobar una solució a curt termini, sembla que s'ha cronificat en el temps. Cal tenir en compte que tot plegat no és nou ni pertany al segle XXI, sinó que tal com demostra el present estudi, amb el sorgiment dels estats nació el desenvolupament de l'arqueologia i la història es va veure condicionat per components ideològics que amaga-

VIDAL SÀnChEZ, Carlota, «L'arqueologia com a element constructor de la identitat nacional». Cercles. Revista d'Història Cultural, 24, 245-249. ISSN: 1139-0158. ISSN-e: 1699-7468. DOI: 10.1344/ cercles2021.24.1010. Data de recepció: 14/3/2021. Data d'acceptació: 3/6/2021. 
ven la necessitat de donar solidesa als orígens de les diverses identitats nacionals. I, com succeeix amb la identitat nacional catalana i espanyola, aquests orígens neixen de l'antagonisme i la confrontació.

Francisco Gracia Alonso és catedràtic de Prehistòria de la Universitat de Barcelona i director del Grup de Recerca en Arqueologia Protohistòrica (GRAP), especialista en la historiografia de l'arqueologia, la guerra del món antic, el patrimoni històric i arqueològic en temps de guerra i en la protohistòria de la península Ibérica. Amb aquesta obra s'endinsa en un dels aspectes més controvertits i alhora més actuals de la historiografia a Espanya i Catalunya: el recurs polític de l'arqueologia i la història com a factors determinants en la construcció d'identitats nacionals diferenciades entre Catalunya i Espanya, des de la segona meitat del segle xix fins a la Guerra Civil Espanyola. Aquest llibre fou publicat en castellà per Edicions de la Universitat de Barcelona el 2018 i compta amb una extensa bibliografia i la consulta de múltiples fonts primàries, com són els informes i la documentació de l'Institut d'Estudis Catalans o els manuscrits d'actors principals en la qüestió, per exemple Enric Prat de la Riba, Pere Bosch i Gimpera o Josep Puig i Cadafalch. La gran quantitat de fonts primàries i secundàries dona, sens dubte, un caràcter eminentment acadèmic a l'obra de Francisco Gracia.

El treball compta amb un total de set-centes cinquanta-set pàgines distribuïdes en quinze apartats que comprenen el període que va entre la segona meitat del segle xix fins a la Guerra Civil. Inicia el seu recorregut en el període previ al I898, moment en què la historiografia espanyola estaria destinada a reconèixer la grandesa i la unió de l'imperi durant l'etapa de la dinastia dels Àustria, un discurs del qual quedava exempta qualsevol idea integradora, com vindicava el catalanisme autonomista del moment. Els jaciments romans van ser objecte d'un especial interès en aquest període, utilitzats com a recurs essencial per propugnar una idea centralitzadora del discurs, basat en valors com l'honor, el sacrifici o l'orgull patri, presentats

Cercles. Revista d'Història Cultural, 24 (2021), 245-249.

ISSN: 1139-0158. e-ISSN: 1699-7468. DOI: 10.1344/cercles2021.24.1010. 
com a referents ideològics i culturals del discurs d'identitat nacional espanyola. Catalunya va comptar des del 1907, moment de naixement de l'Institut d'Estudis Catalans, amb un important treball en la investigació arqueològica, fet diferencial respecte d'altres regions del país i que es va reconèixer des d'Espanya com un instrument d'acció cultural i política al servei del catalanisme, amb el qual s'intentava crear un discurs d'identitat nacional diferenciat.

Lautor demostra la important tasca duta a terme pels centres excursionistes, en relació a la pràctica i la difusió de l'arqueologia a Catalunya. La unió de diversos actors, com van ser els centres excursionistes o l'IEC, va articular un interessant model d'investigació, protecció i difusió que va permetre ampliar la base social i el reconeixement envers la tasca arqueològica que s'anava duent a terme a la regió.

Potser una de les parts més interessants $\mathrm{i}$ innovadores de l'estudi és l'apartat que tracta amb profunditat i solidesa de fonts la manera en què l'arqueologia va ser utilitzada com a element integrador i cohesionador del projecte ideològic de Prat de la Riba. Aquest projecte va recórrer a la construcció d'un relat diferenciador respecte de l'espanyol, vinculant els progressos socials de Catalunya al seu contacte amb el món grec clàssic. Durant aquest període, l'autor afirma un retard important, tant a Catalunya com a Espanya, en el desenvolupament de la ciència arqueològica i les seves metodologies, llastrat pel nacionalisme exclusivista d'ambdós territoris. Gracia s'endinsa en els debats sobre les aportacions de les tesis de Bosch Gimpera al projecte nacionalista de principis del segle xx, en què afirma que el seu desenvolupament seria independent dels treballs del prehistoriador $\mathrm{i}$ que, per tant, no van servir com a coartada ideològica per a la construcció del pensament classicista del Noucentisme.

A la mort de Prat de la Riba, el I917, s'observa un viratge en els fonaments històrics $\mathrm{i}$ arqueològics que havien servit per al programa catalanista fins aleshores, posant en dubte el passat grec a què s'havia 
apel.lat en moments previs. Les elits intel.lectuals d'aleshores apostaren per referenciar la formació de la identitat catalana en l'Edat Mitjana i no en el món clàssic. El món medieval presentà la suma de llenguatge, tradicions i institucions que solidificaven una idea preeminent del moment, el Volkgeist. En aquest moment, el jaciment d'Empúries va perdre el valor i el significat que prèviament se li havia atorgat $\mathrm{i}$, de fet, no tornà a comptar amb una importància destacable fins passada la Guerra Civil.

El penúltim dels apartats s'ocupa de tractar la reforma profunda de la investigació arqueològica duta a terme per Bosch i Gimpera durant el període republicà, que va ser frenada per la falta d'estabilitat política característica dels anys compresos entre I934 i I939, així com la manca d'inversions en el Servei d'Investigacions Arqueològiques. Aquest canvi de paradigma en l'arqueologia que es practicava a Catalunya pretenia establir el caràcter cientificista que ja imperava en el model alemany.

Finalment, l'autor fa un repàs de la dramàtica situació en què va trobar l'exercici de l'arqueologia a Catalunya durant la Guerra Civil, ocupada en cos i ànima a protegir les restes situades a jaciments com el d'Empúries. El patrimoni arquitectònic i arqueològic es va veure sotmès no només a les inclemències bèlliques del moment, sinó també als saquejos produïts per l'esclat revolucionari dels primers mesos de la guerra, així com a les actuacions sobre el patrimoni dictades per la Generalitat de Catalunya amb la intenció d'utilitzar els materials per a les necessitats derivades del conflicte. Aquest període es caracteritza per la urgència del salvament i la protecció del patrimoni arqueològic i de les colleccions i els arxius de referència. Amb el final del període bèlllic, s'arribà al col-lapse definitiu del model d'investigació i el tractament del patrimoni històric i arqueològic a Catalunya que s'havia intentat establir els anys anteriors. La professionalitat intrínseca al programa de Bosch i Gimpera va desaparèixer per deixar pas als erudits locals, a les mans dels quals quedà la investiga-

Cercles. Revista d'Història Cultural, 24 (2021), 245-249.

ISSN: 1139-0158. e-ISSN: 1699-7468. DOI: 10.1344/cercles2021.24.1010. 
ció arqueològica i històrica. Aquest model, aplicat durant el franquisme, va impossibilitar la professionalització de la recerca. Figures com Bosch i Gimpera o Puig i Cadafalch patiren l'exili, com fou el cas del primer, o l'aillament en l'estructura administrativa, com succeí amb el segon.

En definitiva, ens trobem davant d'un llibre que ens aporta una extensa explicació sobre les vicissituds que va experimentar la investigació arqueològica i històrica en un període transcendental de la nostra història, i que ens ofereix una anàlisi dels diversos usos polítics d'ambdues disciplines, així com de la seva significació i utilitat en la creació de la identitat nacional, tant catalana com espanyola. El llibre representa un acostament a l'ús de la historiografia de l'arqueologia des de les idees nacionalistes de l'espai català i espanyol, i demostra fins a quin punt l'arqueologia com a disciplina científica fou emprada en la creació d'identitats nacionals de dalt a baix. Aquestes representacions de les identitats nacionals van necessitar la creació d'una tradició nacional inventada, uns orígens patris que acompanyessin els valors de la nació, unes fites en què l'arqueologia va resultar que podia ser una gran aliada.

Copyright (C) 202I. Aquesta obra està subjecta a una llicència de Creative Commons mitjançant la qual qualsevol explotació n'haurà de reconèixer els autors, citats a la referència que apareix a l'inici del document. 